http://jmscr.igmpublication.org/home/

ISSN (e)-2347-176x ISSN (p) 2455-0450

crossref DOI: https://dx.doi.org/10.18535/jmscr/v8i6.115

\title{
Analysis of Histopathological Spectrum of Kidney Lesions - An Institutional Autopsy Study of One Year
}

Authors

\section{Dr Suwarna B Patil ${ }^{1}$, Dr Shriram Chopade ${ }^{2}$, Dr Swarada V Kangate ${ }^{3}$,} Dr Manjiri G Khade ${ }^{4}$, Dr Pradeep S Umap ${ }^{5}$, Dr Pradeep Rudra ${ }^{6}$

${ }^{1,2}$ Associate Professor, Department of Pathology, GMC, Akola, Maharashtra, India

${ }^{3,4}$ Assistant Professor, Department of Pathology, GMC, Akola, Maharashtra, India

${ }^{5}$ Professor and Head, Department of Pathology, GMC, Akola, Maharashtra, India

${ }^{6}$ Junior Resident, Department of Pathology, GMC, Akola, Maharashtra, India

*Corresponding Author

Dr Manjiri G Khade

Assistant Professor, Department of Pathology, GMC, Akola, Maharashtra, India - 444001

\begin{abstract}
Introduction: Autopsy provides an opportunity to uncover the changing patterns of disease in modern era. Chronic Renal Disease is a global health crisis, with an estimated worldwide prevalence of $8-16 \%$. So the current study is undertaken with the aims to analyze varied spectrum of renal lesions detected on autopsy and to study effect of associated co-morbidities for renal pathology.

Material and Methods: Present retrospective cross sectional study of both Medico-legal and clinical autopsy cases with total of 260 cases was carried out at Tertiary care center during July 2018 to June 2019. Microscopic histopathological examination was done and correlated with clinical details.

Results: We found 105 (40.38\%) cases with renal pathologies, while 155 cases $(59.61 \%)$ showed normal histology, with most commonly affecting 21-30 years of age. Male to female ratio was 1.7:1. Nonglomerular lesions were more common than glomerular.

Conclusion: Present study reveals many renal lesions which produce no functional derangement and are detected for the first time at autopsy.
\end{abstract}

Keywords: Autopsy, Kidney lesion, Histopathology, Spectrum, Diabetes, Hypertension.

\section{Introduction}

Autopsy study is of great diagnostic and educational value similar to the dictum "Mortui Vivos Docent". The Autopsy data is the best teaching aid to the Clinicians and Pathologists inspite of profound recent advances in diagnostic modalities. Autopsy studies uncover the changing patterns of disease in modern era. Gross and microscopic examination of both Clinical and
Medico-legal autopsy organs give insight into the possible cause of death. Thus, Pathologists play key role in determining the exact incidence, precise cause and mechanism of death through autopsy ensuring that in future appropriate preventive strategies are implemented.

Chronic Renal Disease (CKD) is a global health crisis, with an estimated worldwide prevalence of $8-16 \%$. One in five men and one in four women 
have CKD. ${ }^{2}$ Kidneys are known to be "silent killers" and CKD is responsible for great deal of morbidity and mortality. Thus, CKD is now recognized as a major global public health issue and is an independent risk factor for cardiovascular disease. ${ }^{3,4}$ The increased prevalence of CKD is a consequence of enormous spike of risk factors like hypertension (HT), diabetes mellitus (DM), dyslipidemia and obesity. ${ }^{5}$

CKD is reported to be the $9^{\text {th }}$ leading cause of death in the United States. ${ }^{6}$ In India prevalence of CKD is approximately $17 \%$ out of which $43 \%$ have HT and $18 \%$ have DM. Thus, globally most common causes of CKD are DM and HT.

Due to silent progressive nature of CKD affected largely by HT, DM, dyslipidemia, obesity, nephrolithiasis and drug interactions - the pathologic examination of renal tissue in autopsy would throw light on renal histologic changes of general population of that specific region. This valuable information would certainly prevent CKD which most of the times tend to be asymptomatic and undiagnosed till death. Accidentally acute renal injury in the form of Acute Tubular Necrosis (ATN) occurs in $22 \%$ of hospitalizations and is associated with fourfold increased mortality rate. Thus, high rate of acute and chronic renal diseases are expected at autopsy. $^{7}$

The aim of the present study was 1) To analyze varied spectrum of renal lesions detected on autopsy and 2) to study effect of associated co morbidities like HT, DM on renal pathology.

\section{Material and Methods}

Present study was a retrospective cross sectional study of both Medico-legaland clinical autopsy cases with total of 260 cases carried out at Tertiary care center during July 2018 to June 2019. Detailed clinical history was retrieved from the clinical records. We received kidney specimen either in pieces or whole kidney. Weight and gross findings like cortical thickness, decortication, pelvi-calyceal system were analyzed. Specimens were fixed in $10 \%$ formalin. Representative sections from cortex and medulla were taken and histopathological processing was done. Slides were stained with Haematoxylene and Eosin $(\mathrm{H} \&$ E) and studied. Whenever required special stains like Periodic Acid Schiff (PAS), Reticulin and Congo red were used. Microscopic histopathological examination was done by Senior Pathologist and results were tabulated.

\section{Results}

In present study, 260 autopsy cases were studied for kidney lesions over a period of one year. We found $105(40.38 \%$ ) cases with renal pathologies, while 155 cases $(59.61 \%)$ showed normal histology.

The renal findings were categorized in to glomerular and non-glomerular lesions.

As shown in Table 1 there is male preponderance over females with male to female ratio being 1.76:1. Youngest was one day male with Autosomal recessive polycystic kidney (ARPCKD) and oldest was 80 years with renal cell carcinoma -chromophobe type (RCC). Maximum age group affected was 21 to 30 years.

As shown in Table 2 out of 105 cases 20(19\%) deaths were due to primary renal cause and commonest reasons were diabetic nephropathy and Chronic Pyelonephritis (CPN). Rare causes were inherited renal disorders like ARPCKD, Autosomal Dominant Polycystic Kidney Disease (ADPCKD) and renal dysplasia. Also incidental findings included one case of chromophobe RCC and one case of Collecting duct carcinoma.

As shown in Table 3, 85 cases $(71 \%)$ showed many associated renal pathologies when cause of death was from varied reasons. Most common among them were sudden cardiac death from Myocardial infarction (MI), coronary atherosclerosis and pneumonia. Young females with maternal deaths also showed ischemic Acute Tubular Necrosis (ATN). Cases of poisoning and snake bite showed toxic ATN.

As shown in Table 4, Renal arteriosclerosis in the form of benign and malignant nephrosclerosis associated with HT was the most common renal 
pathology. Second common was ischemic and toxic ATN seen with sudden death from cardiac origin, poisoning and maternal mortality.

Table 1: Age and Sex Distribution $(\mathrm{n}=105)$

\begin{tabular}{|l|c|c|c|}
\hline Age Range (years) & Male & Female & Total \\
\hline 1Day- 1 & 3 & 3 & 6 \\
\hline $\mathbf{1 - 1 0}$ & 4 & 1 & 5 \\
\hline $\mathbf{1 1 - 2 0}$ & 4 & 4 & 8 \\
\hline $\mathbf{2 1}-\mathbf{3 0}$ & 11 & 14 & 25 \\
\hline $\mathbf{3 1 - 4 0}$ & 14 & 3 & 17 \\
\hline $\mathbf{4 1 - 5 0}$ & 9 & 3 & 12 \\
\hline $\mathbf{5 1}-\mathbf{6 0}$ & 9 & 7 & 16 \\
\hline $\mathbf{6 1}-\mathbf{7 0}$ & 11 & 2 & 13 \\
\hline $\mathbf{7 1}-\mathbf{8 0}$ & 2 & 1 & 3 \\
\hline Total & $\mathbf{6 7}$ & $\mathbf{3 8}$ & $\mathbf{1 0 5}$ \\
\hline
\end{tabular}

Table 2: Deaths due to Primary Renal cause ( $\mathrm{n}=$ 20)

\begin{tabular}{|l|l|c|c|}
\hline $\begin{array}{l}\text { Sr. } \\
\text { No }\end{array}$ & Cause & $\begin{array}{c}\text { Numb } \\
\text { er }\end{array}$ & $\begin{array}{c}\text { Percenta } \\
\text { ge \% }\end{array}$ \\
\hline $\mathbf{1}$ & Diabetic Nephropathy & 5 & 25 \\
\hline $\mathbf{2}$ & CPN with Pyonephrosis & 4 & 20 \\
\hline $\mathbf{3}$ & Nephrolithiasis & 3 & 15 \\
\hline $\mathbf{4}$ & Glomerulonephritis (FSGN)* & 2 & 10 \\
\hline $\mathbf{5}$ & AR PCKD** & 2 & 10 \\
\hline $\mathbf{6}$ & AD PCKD + & 1 & 5 \\
\hline $\mathbf{7}$ & Renal Dysplasia & 1 & 5 \\
\hline $\mathbf{8}$ & Renal Cell Carcinoma & 1 & 5 \\
\hline $\mathbf{9}$ & Collecting Duct Carcinoma & 1 & 5 \\
\hline & Total & $\mathbf{2 0}$ & $\mathbf{1 0 0}$ \\
\hline
\end{tabular}

Focal segmental Glomerulonephritis

**Autosomal recessive polycystic kidney

†Autosomal dominant polycystic kidney

Table 3: Secondary Renal changes associated with other causes of death $(n=85)$

\begin{tabular}{|l|l|c|c|}
\hline $\begin{array}{l}\text { Sr. } \\
\text { No }\end{array}$ & Primary Organ System & 24 & 28.1 \\
\hline $\mathbf{1}$ & $\begin{array}{l}\text { Cardiovascular System } \\
\text { CAD*/MI)** }\end{array}$ & 15 & 18 \\
\hline $\mathbf{2}$ & $\left.\begin{array}{l}\text { Respiratory } \\
\text { Pneumonia/TB+/CVC }\end{array}\right)$ & 10 & 12 \\
\hline $\mathbf{3}$ & Maternal Death & 07 & 8.6 \\
\hline $\mathbf{4}$ & Poison & 06 & 7.4 \\
\hline $\mathbf{5}$ & Fetal Death & 04 & 4.7 \\
\hline $\mathbf{6}$ & Sickle Cell Disease & 04 & 4.7 \\
\hline $\mathbf{7}$ & Unknown Cause & 03 & 3.5 \\
\hline $\mathbf{8}$ & Hanging & 02 & 2.2 \\
\hline $\mathbf{9}$ & Hepatobiliary System & 02 & 2.2 \\
\hline $\mathbf{1 0}$ & Road Traffic Accident & 02 & 2.2 \\
\hline $\mathbf{1 1}$ & Septecimia with Fever & 02 & 2.2 \\
\hline $\mathbf{1 2}$ & Snake Bite & 02 & 2.2 \\
\hline $\mathbf{1 3}$ & Gastrointestinal Tract & 01 & 1 \\
\hline $\mathbf{1 4}$ & Sun Stroke & 01 & 1 \\
\hline $\mathbf{1 5}$ & Drowning & $\mathbf{8 5}$ & $\mathbf{1 0 0}$ \\
\hline & Total & & \\
\hline
\end{tabular}

*Coronary artery disease

**Myocardial Infarction

†Tuberculosis

||Chronic venous congestion
Table 4: Histopathological Findings seen with Renal diseases $(n=105)$

\begin{tabular}{|l|l|c|c|}
\hline Sr.No & Renal Changes changes & Number & Percentage \\
\hline $\mathbf{1}$ & $\begin{array}{l}\text { Renovascular } \\
\text { Arteriosclerosis) }\end{array}$ & 38 \\
\hline $\mathbf{2}$ & Acute Tubular Necrosis & 18 & 17 \\
\hline $\mathbf{3}$ & CPN with Pyonephrosis & 10 & 9.5 \\
\hline $\mathbf{4}$ & End Stage Renal Disease & 09 & 8.6 \\
\hline $\mathbf{5}$ & Diabetic nephropathy & 05 & 4.7 \\
\hline $\mathbf{6}$ & Glomerulosclerosis & 04 & 3.8 \\
\hline $\mathbf{7}$ & $\begin{array}{l}* \text { SCD with Vasoocclusive } \\
\text { crisis }\end{array}$ & 04 & 3.8 \\
\hline $\mathbf{8}$ & Nephrolithiasis & 03 & 2.8 \\
\hline $\mathbf{9}$ & $* *$ TB(Miliary Kidney) & 02 & 1.9 \\
\hline $\mathbf{1 0}$ & Dialysis Changes & 02 & 1.9 \\
\hline $\mathbf{1 1}$ & +FSGN & 02 & 1.9 \\
\hline $\mathbf{1 2}$ & AR PCKD & 02 & 1.9 \\
\hline $\mathbf{1 3}$ & AD PCKD & 01 & 0.9 \\
\hline $\mathbf{1 4}$ & Renal Dysplasia & 01 & 0.9 \\
\hline $\mathbf{1 5}$ & Renal Cell Carcinoma & 01 & 0.9 \\
\hline $\mathbf{1 6}$ & Collecting Duct Carcinoma & 01 & 0.9 \\
\hline & Total & $\mathbf{1 0 5}$ & $\mathbf{1 0 0}$ \\
\hline
\end{tabular}

* Sickle cell diasease

**Tuberculosis

†Focal Segmental Glomerulonephritis

Table 5: Male to female ratio in comparable other studies

\begin{tabular}{|l|l|l|}
\hline Sr. No & Study & Male to Female ratio \\
\hline 1 & ${\text { SNS Yadav et } \mathrm{al}^{10}}^{10}$ & $1.8: 1$ \\
\hline 2 & ${\text { P.S. Mulay et } \mathrm{al}^{11}}^{11}$ & $2.1: 1$ \\
\hline 3 & AmandeepKaur et $\mathrm{al}^{12}$ & $4: 1$ \\
\hline 4 & Present study & $1.7: 1$ \\
\hline
\end{tabular}

Table 6: Maximum affected age group comparable studies

\begin{tabular}{|l|c|c|}
\hline Sr.No & Study & Age group \\
\hline 1 & Amandeep Kaur et al $^{12}$ & $21-40$ \\
\hline 2 & P.S. Mulay et al $^{11}$ & $20-40$ \\
\hline 3 & SNS Yadav et al $^{10}$ & $31-50$ \\
\hline 4 & Present study $^{10}$ & $21-30$ \\
\hline
\end{tabular}

Table 7: Comparison of percentage of histologically normal kidneys in autopsy

\begin{tabular}{|l|c|c|c|}
\hline Sr.No & Study & $\begin{array}{c}\text { Year of } \\
\text { Study }\end{array}$ & Cases \\
\hline 1 & SNS Yadav et al $^{10}$ & $1980-87$ & $\begin{array}{c}422 \text { out of } 491 \\
(85.95 \%)\end{array}$ \\
\hline 2 & Utsa et al $^{13}$ & 2014 & $\begin{array}{c}23 \text { out of } 55 \\
(41 \%)\end{array}$ \\
\hline 3 & $\begin{array}{c}\text { Vaneetkaursandhu et }_{\text {al }^{14}} \\
\text { (2) }\end{array}$ & 2017 & $\begin{array}{c}27 \text { out of } 120 \\
(22 \%)\end{array}$ \\
\hline 5 & Amandeep Kaur et al $^{12}$ & 2018 & $\begin{array}{c}25 \text { out of } 100 \\
(25 \%)\end{array}$ \\
\hline
\end{tabular}




\section{JMSCR Vol||08||Issue||06||Page 600-606||June}

Table 8: Comparison of percentage of glomerular lesions involved with other studies

\begin{tabular}{|c|c|c|}
\hline Sr.No & Study & cases \\
\hline 1 & AmandeepKaur et al $^{12}(2018)$ & 17 out of $100(17 \%)$ \\
\hline 2 & Hailemariam S et al ${ }^{15}$ ( 2001) & 28 out of $273(11.81 \%)$ \\
\hline 3 & P.S. Mulay et $\mathrm{al}^{11}(2020)$ & 78 out of $550(14.17 \%)$ \\
\hline 4 & Present study (2020) & 11 out of $105(10.47 \%)$ \\
\hline
\end{tabular}

Figure 1: Gross and Microscopy of Renal Lesions
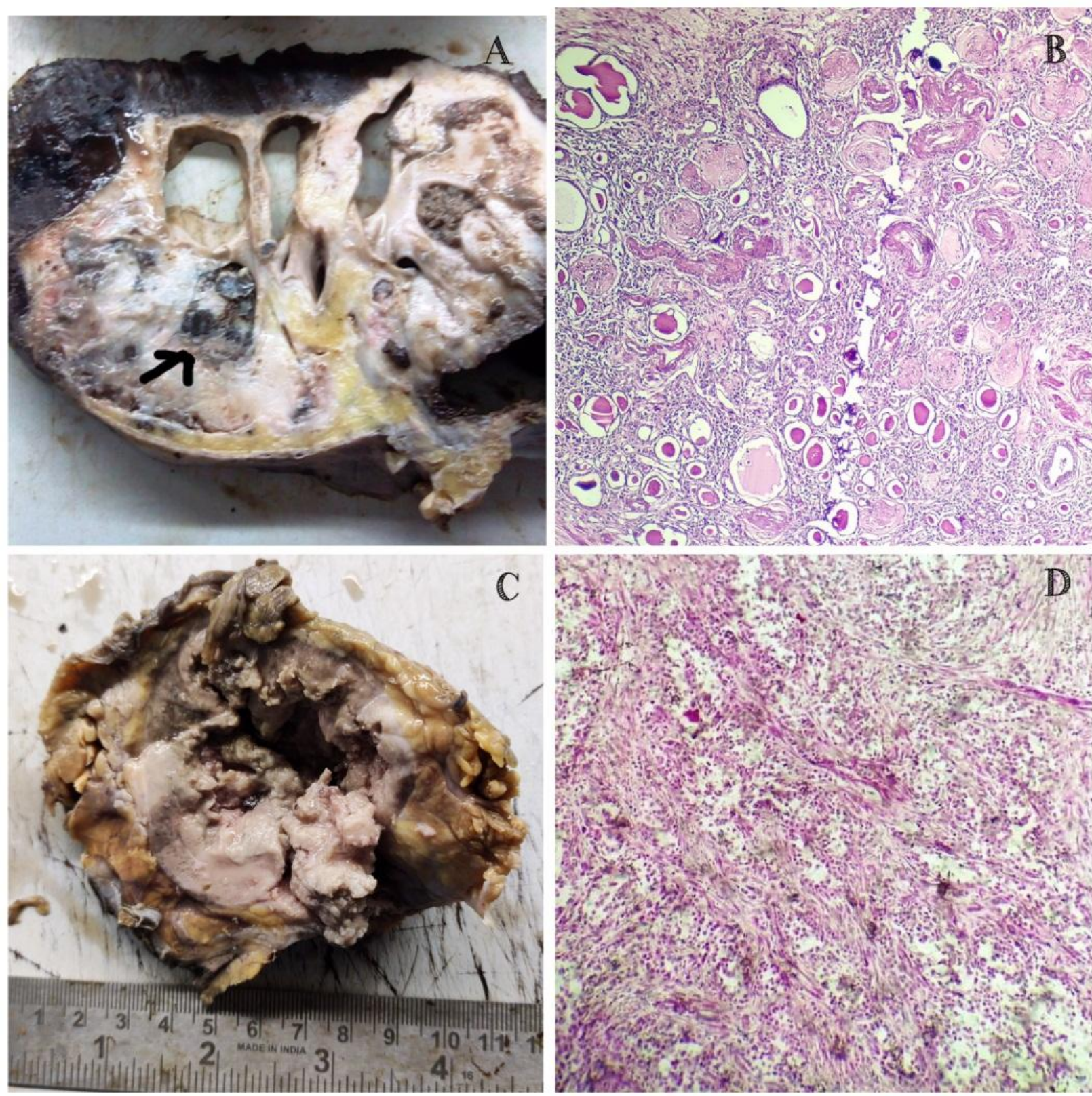

A: Gross Photo of Nephrolithiasis with Pyelonephrosis

B: Microphotograph of chronic pyelonephritis, (HE, 200X)

C: Gross photo of Collecting Duct Carcinoma of Renal Pelvis

D: Microphotograph of Collecting Duct Carcinoma of Renal Pelvis (HE, 400X) 


\section{JMSCR Vol||08||Issue||06||Page 600-606||June}

Figure 2: Microscopic Findings of Renal Lesions
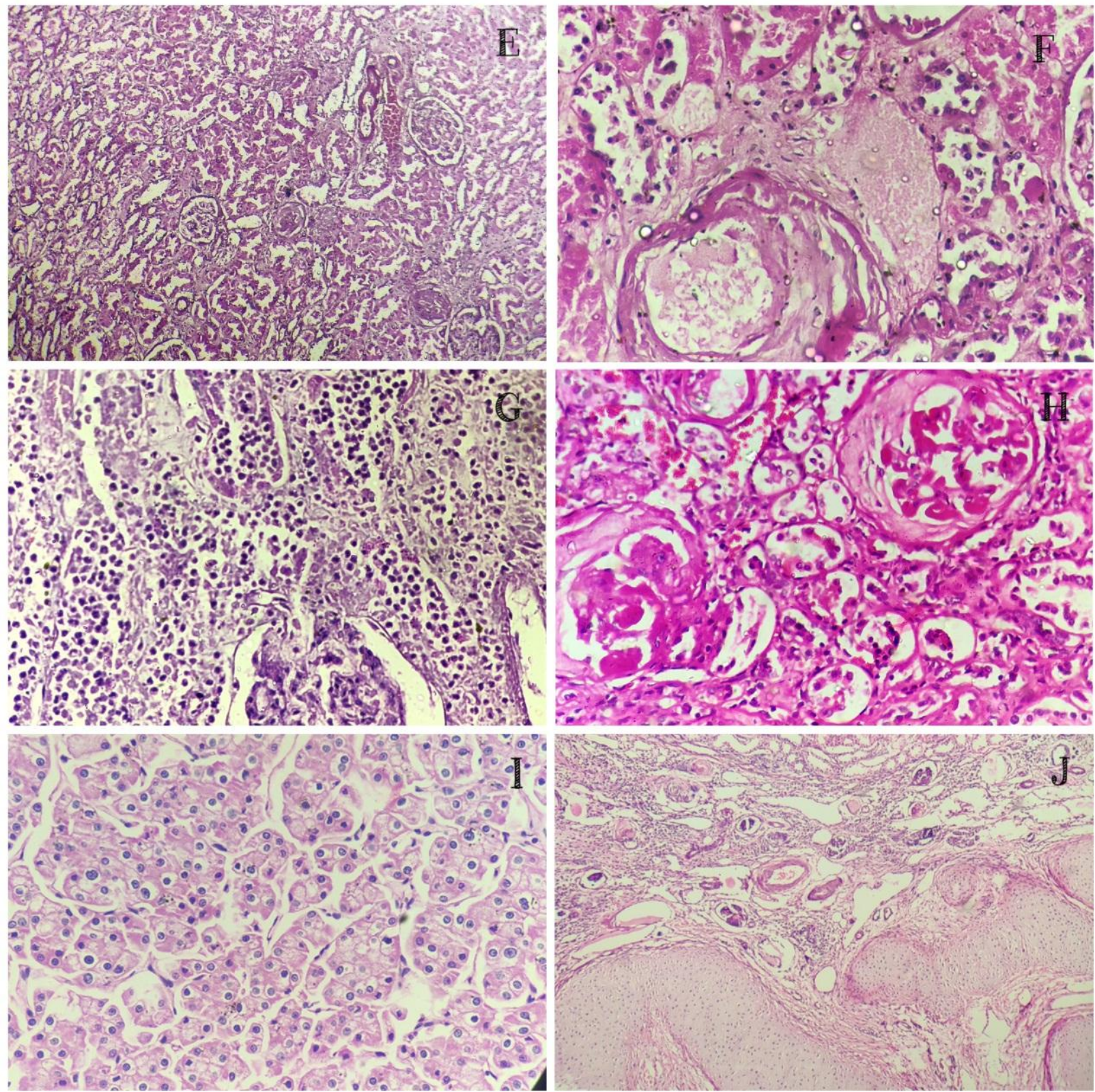

E: Benign Nephrosclerosis showing hyaline arteriosclerosis (HE, 200X)

F: Malignant Nephrosclerosis showing onion skin lesion and fibrinoid necrosis (HE, 400X)

G: Acute Tubular Necrosis (ATN) - Toxic type showing desquamation of tubular epithelium (HE, 200X)

H: Diabetic Nephropathy showing KW lesions (HE, 400X)

I: Chromophobe RCC showing perinuclearhof (HE, 400X)

J: Multicystic Renal Dysplasia showing primitive cartilage (HE, 200X)

\section{Discussion}

Distribution of renal lesions vary with geographic area, age, gender, environmental, nutritional and genetic factors. ${ }^{8,9}$

In the present study, among 260 autopsies studied during one year, $105(40.38 \%)$ cases showed kidney lesions and 155(59.61\%) cases showed normal histology.
It was observed in all studies that there is male predominance. Male to female ratio in present study was $1.76: 1$, that goes parallel with studies mentioned in table 5 .

In our study commonest age group affected was 21 to 30 years, which was comparable to studies mentioned in table 6 . 
Kidneys unaffected and kidneys involved with pathologies detected in autopsies varies from region to region as shown in table 7 .

In our present study analysis, glomerular lesions were less compared to non-glomerular lesions. Other studies which support our findings are as in table 8.

Most common histological finding was renovascular lesions (38\%) in the form of benign nephrosclerosis with hyaline change (Fig 2E) and malignant nephrosclerosis showing onion skin lesions with fibrinoid necrosis (Fig 2F) comparable with study by Sandhu et $\mathrm{al}^{14}$ and Marie E Perrone et al ${ }^{16}$

Second common finding was acute tubular necrosis ATN (17\%) (Fig 2G). ATN is most common and important cause of acute renal failure (ARF) characterized by sudden cessation of renal function. It has two morphological forms ischemic and toxic ${ }^{17}$. It was comparable with study by Amandeep kaur et al ${ }^{12}$ and Sandhu et al ${ }^{14}$ Third common finding was CPN associated with nephrolithiasis $(9.5 \%)$ (Fig 1A, 1B). Urinary calculi are worldwide in distribution affecting $2 \%$ of population in second and third decade of life ${ }^{17}$. These findings are similar to study by Sandhu et al. $^{14}$

A very important finding was renal changes associated with Diabetic nephropathy. CKD with Renal failure accounts for more than $10 \%$ of all diabetic deaths. Renal complications are more severe and develop early in Type I diabetes $-40 \%$ as compared to $20 \%$ seen in Type II diabetes. Variety of lesions are seen in the form of diffuse glomerulosclerosis, capsular drop, fibrin cap, Kimmelstiel Wilson (KW) lesions (Fig 2H), papillary necrosis and Armann iEbstein lesions. ${ }^{17}$ We reported $4.7 \%$ deaths due to Diabetic nephropathy while Marie E Perrone et $\mathrm{al}^{16}$ found $20 \%$ of diabetic nephropathies.

Rare lesion was cystic renal diseases. Cystic Renal lesions may be congenital or acquired, neoplastic or non-neoplastic. They occur at any age from newborn to old age and are classified in to Potter type I, II, III. We reported three such rare cases of which one is Multicystic Renal Dysplasia ( Potter II) (Fig 2J). Second is ARPCKD (Potter I) and third case is of ADPCKD (Potter III).

RCC comprise 70 to $80 \%$ of all renal cancers affecting elderly males. ${ }^{17} \mathrm{We}$ reported two rare lesions of Chromophobe RCC (Fig 2I) and Collecting duct carcinoma of renal pelvis. (Fig 2C, 2D). These findings are comparable with study by Sandhu et $\mathrm{al}^{14}$ and Mulay et al. ${ }^{11}$

Sickle cell disease is a very common haemolyticanaemia in Vidarbha region of Maharashtra. We reported four cases of Sickle cell nephropathy while Marie E Perrone et al ${ }^{16}$ reported only one case.

Our study also included two cases of Miliary Renal Tuberculosis.

\section{Conclusion}

Autopsy is an indispensable part of Medicine. Autopsy study reveals many rare and undiagnosed histologic lesions which are not clinically detected. Many renal lesions produce no functional derangement and are detected for the first time at autopsy.

Present study showed that non-glomerular lesions are more common than glomerular lesions .HT and DM arethe main impending risk factors. Our study provides satisfactory data with respect to morphological spectrum of renal lesions at autopsy. However, it may not reflect the actual renal lesions of the entire population.

In this modern era also, autopsy study throws immense light on pathogenesis of disease, reveals hazardous effects of drug therapies and associated comorbidities like HT, DM, dyslipidemia and obesity, which are preventable.

Acknowledgment: Department of Forensic Medicine

\section{References}

1. Reddy, KSN \&Murty, Om. (2017). The Essentials of Forensic Medicine and Toxicology - 34th Edition by KSN Reddy and OP Murty. 
2. Jha V, Garcia-Garcia $G$, Iseki $K$, et al. Chronic kidney disease: global dimension and perspectives [published correction appears in Lancet. 2013 Jul 20;382(9888):208]. Lancet. 2013;382(9888):260- 272.

3. Levey AS, Atkins R, Coresh J, et al. Chronic kidney disease as a global public health problem: approaches and initiatives - a position statement from Kidney Disease Improving Global Outcomes. Kidney Int. 2007;72(3):247- 259.

4. Schiffrin EL, Lipman ML, Mann JF. Chronic kidney disease: effects on the cardiovascular system. Circulation. 2007;116(1):85- 97.

5. Nagata M, Ninomiya T, Doi Y, et al. Trends in the prevalence of chronic kidney disease and its risk factors in a general Japanese population: the Hisayama Study [published correction appears in Nephrol Dial Transplant. 2010 Dec;25(12):4123-4]. Nephrol Dial Transplant. 2010;25 (8): 2557- 2564.

6. Xu J, Murphy SL, Kochanek KD, Arias E. Mortality in the United States, 2015. NCHS Data Brief. 2016;(267):1- 8.

7. Wang HE, Muntner P, Chertow GM, Warnock DG. Acute kidney injury and mortality in hospitalized patients. Am J Nephrol. 2012;35(4):349- 355.

8. Kurnatowska I, Jędrzejka D, Małyska A, Wągrowska-Danilewicz M, Danilewicz M, Nowicki M. Trends in the incidence of biopsy-proven glomerular diseases in the adult population in central Poland in the years 1990-2010. Kidney Blood Press Res. 2012;35(4):254- 258.

9. Zaza G, Bernich P, Lupo A; 'Triveneto' Register of Renal Biopsies (TVRRB). Incidence of primary glomerulonephritis in a large North-Eastern Italian area: a 13-year renal biopsy study. Nephrol Dial Transplant. 2013;28(2):367- 372.
10. Dr. SNSYadav. Histomorphological Study of Kidney Lesions In Autopsy- An Original Eight Year Study. IOSR Journal of Dental and Medical Sciences (IOSR-JDMS), vol.18,no.5,2019,pp 50-54.

11. Dr P.S. Mulay, Dr Aanchal Khosla. Kidney Lesions in autopsy:3-year study in a Tertiary Health care. Journal of Medical Sciences And Clinical Research,vol 08 Issue 02 Feb2020

12. Amandeep Kaur, Vijay Kumar Bodal, Puneet Garg, Akashdeep Aggarwal. Histopathological Spectrum of Kidney lesions In autopsy- A study of 100 cases. JMSCR Vol.06 Issue 02 Feb 2018

13. Utsaet al Histomorphological and immune alteration in autopsied kidneys. Saudi. Med. Jr.2014;35:1331-38.

14. Vaneet Kaur Sandhu, Arun Puri and Navtej Singh. Histomorphological Spectrum of Renal Lesion in An Autopsy Study. Annals of Pathology and lab medicine.2017 (4)

15. Hailemariam $S$ et al. Renal pathology and premortem clinical presentation of Caucasian patients withs AIDS; An autopsy study from the eraprior to antiretroviral therapy. Swiss Med mwkly2001;131:412-17

16. Marie E Parrone, Anthony Chang and Kammi J Henriksen. Medical renal disease are frequent but often unrecognized in adult autopsies. Modern pathology (2018)31,365373

17. Kumar V, Abbas AK, Aster JC. Robbins and Cotran Pathologic Basis of Disease, South Asia Edition. Reed Elsevier: New Delhi. 2015. 